\title{
DESENVOLVIMENTO DE METODOLOGIA DE COLETA E MANUTENÇÃO EM LABORATÓRIO DA FORMIGA INVASORA PARATRECHINA LONGICORNIS LATREILLE (HYMENOPTERA: FORMICIDAE)
}

\author{
D.R. Solis ${ }^{1}$, O.C. Bueno', T.C. Moretti ${ }^{2}$
}

${ }^{1}$ Universidade Estadual Paulista, Instituto de Biociências, Departamento de Biologia, Centro de Estudos de Insetos Sociais, Av. 24-A, 1515, CEP 13506-900, Rio Claro, SP, Brasil. E-mail: entomo75@yahoo.com

\section{RESUMO}

\begin{abstract}
O gênero Paratrechinaé um grupo cosmopolita, com algumas espécies invadindo residências e hospitais. No Brasil, as espécies mais importantes são: Paratrechina fulva e Paratrechina longicornis. Apesar do destaque como pragas urbanas, há uma escassez de informações sobre sua biologia, devido às pesquisas com as formigas urbanas serem recentes em nosso país e pela dificuldade na manutenção de $P$. longicornis em laboratório. Assim, este estudo pretendeu desenvolver uma metodologia adequada de coleta e outra para a manutenção em laboratório de P. longicornis. Para as coletas foram analisadas quatro metodologias, enquanto para a manutenção em laboratório foram avaliados: os tipos de recipientes onde as colônias permaneceriam alojadas e os itens alimentares que comporiam a dieta. Nas coletas das colônias a metodologia mais adequada foi aquela em que se utilizou o aspirador entomológico. $\mathrm{Na}$ manutenção das colônias, o recipiente mais adequado foi o tubo de ensaio com algodão embebido em água e, quanto aos testes de atratividade alimentar, as operárias têm preferências por líquidos açucarados e por insetos mortos, principalmente cupins. Além disso, ocorreram duas infestações por ácaros das famílias Acaridae, Macrochelidae (gênero Macrocheles) e Uropodidae nas colônias de P. longicornis, que ocasionaram uma significativa mortalidade das colônias, devido a um desequilíbrio no comportamento social.
\end{abstract}

PALAVRAS-CHAVE: Formicinae, formigas urbanas, formiga louca, ácaros, alimentação.

\section{ABSTRACT}

DEVELOPMENTOF AMETHODOLOGYOFCOLLECTION ANDREARINGOFTHEINVASIVE ANT PARATRECHINA LONGICORNIS LATREILLE (HYMENOPTERA: FORMICIDAE) IN THE LABORATORY. The genus Paratrechina is a cosmopolitan group, with some species invading residences and hospitals. In Brazil, the most important species are:Paratrechinafulva and Paratrechina longicornis. In spite of the importance of these species as urban pests, there is a lack of information on their biology, since studies on urban ants are rather recent in our country and also due to the difficulty of keeping colonies of $P$. longicornis in the laboratory. Therefore, the present study was aimed at developing two methodologies: one suitable for collecting and another for keeping colonies of P. longicornis in the laboratory. Concerning the collections, four methodologies were analyzed, while for keeping colonies in the laboratory, the types of containers where the colonies would be stored as well as the food items that would comprise their diet were evaluated. The most adequate methodology for collecting was the one performed using an entomological aspirator. Regarding the maintenance of colonies, the most adequate container was the test tube with cotton steeped in water, while in the tests on food attractiveness, the workers showed preference for sugary liquids and dead insects, mainly termites. Moreover, two infestations of mites from the families Acaridae, Macrochelidae (genus Macrocheles) and Uropodidae in the colonies of $P$. longicornis have occurred, which caused a significant mortality of the colonies, due to an unbalance in the social behavior of the ants.

KEY WORDS: Formicinae, tramp species, crazy ant, mites, feeding.

\footnotetext{
${ }^{2}$ Universidade Estadual Paulista, Instituto de Biociências, Departamento de Parasitologia, Botucatu, SP, Brasil.
} 


\section{INTRODUÇÃO}

As formigas urbanas foram disseminadas por todo o planeta pelo comércio. Nas regiões temperadas, elas foram favorecidas pela existência de modernas habitações aquecidas, permitindo a sobrevivência das colônias ao inverno. Além disso, o uso indiscriminado de inseticidas intensificou a fragmentação e a formação de novas colônias (BERNDT; EICHLER, 1987). Elas podem causar sérios problemas em edificações humanas, principalmente residências e hospitais. Quando presentes em residências causam incômodo com seu aparecimento em cozinha, despensas de alimentos e nos banheiros (EICHLER, 1962, 1978). Em hospitais, as formigas podem atuar como vetores mecânicos de microrganismos patogênicos (Fowler et al., 1993; MOREIRA et al., 2005; Lise et al., 2006).

Das mais de 12.000 espécies de formigas descritas no mundo (Agosti;Johnson, 2008), aproximadamente 50 são consideradas pragas urbanas (ROBINSON, 1996). Estas espécies compartilham um conjunto de características que permitiram a sua adaptação e sobrevivência no ambiente urbano, destacando: ninhos pouco estruturados propensos à migração ao menor sinal de perturbação, populações unicoloniais, alta agressividade interespecífica, poliginia, ausência de vôo nupcial com o acasalamento ocorrendo no interior ou na entrada do ninho, e as operárias são normalmentedetamanhodiminutoemonomórficas (PASSERA, 1994).

O gênero Paratrechina, pertencente à subfamília Formicinae, ocorre em regiões tropicais e subtropicais, sendoquejá foram descritas174 espécies esubespécies (Botton et al., 2005). Várias espécies deste gênero foram espalhadas pelo planeta através do comércio, invadindo diversos tipos de edificações humanas, principalmente residências e hospitais. As espécies mais importantes que ocorrem nas Américas são: Paratrechina bourbonica, Paratrechina fulva, Paratrechina longicornis e Paratrechina vividula (Trager, 1984). No Brasil, $P$. fulva é considerada uma espécie nativa e $P$. longicornis uma espécieintroduzida, sendoqueambas são relatadas como pragas importantes em ambientes urbanos (Fowleret al., 1993; Delabie et al., 1995;Silva; LOECK, 1999; ZARZUELA et al., 2002).

A maioria dos estudos sobre este gênero foi realizada em países de clima temperado, principalmente as espécies de importância econômica. No Brasil, apesar de P. fulva e P. longicornis terem uma posição de destaque como pragas no ambiente urbano, há uma escassez de informações sobre sua biologia, devido às pesquisas com as formigas domiciliares serem recentes em nosso país e pela dificuldade na manutenção de $P$. longicornis em laboratório (CAMPOSFARINHA, 2005). Desta maneira, o presente estudo pre- tendeu desenvolver uma metodologia adequada de coleta e outra para a manutenção em laboratório de $P$. longicornis.

\section{MATERIAL E MÉTODOS}

As colônias de P. longicornis foram coletadas em áreas urbanas dos Municípios de Campinas (22 $\left.{ }^{\circ} 49^{\prime} 16.58^{\prime \prime} S, 47^{\circ} 05^{\prime} 20.33^{\prime \prime} \mathrm{W}\right)$, Rio Claro $\left(22^{\circ} 23^{\prime} 52.20^{\prime \prime} S, 47^{\circ} 32^{\prime} 50.20^{\prime \prime} W\right)$ e São Paulo $\left(23^{\circ} 35^{\prime} 21.88^{\prime \prime} \mathrm{S}, 46^{\circ} 39^{\prime} 00.88^{\prime \prime} \mathrm{W}\right)$ e transferidas para ninhos artificiais, que foram mantidos em laboratório no Centro de Estudos de Insetos Sociais, no Instituto de Biociências da UNESP (Campus Rio Claro), em condições controladas de temperatura $\left(25^{\circ} \mathrm{C} \pm 2^{\circ} \mathrm{C}\right)$ e umidade relativa $(60 \% \pm 10 \%)$. Os ninhos foram mantidos no interior de bandejas plásticas ( $52 \mathrm{~cm}$ de comprimento, $44 \mathrm{~cm}$ de largura e $8 \mathrm{~cm}$ de altura), sendo que nas bordas de cada bandeja foi aplicada uma camada de Teflon-30 (Dupont) acrescida de talco, para evitar a fuga das formigas. A alimentação das colônias constituiu-se inicialmente de adultos de Anagasta kuehniella (Lepidoptera: Pyralidae) e larvas de Tenebrio molitor (Coleoptera: Tenebrionidae) e açúcar diluído em água a $25 \%$, com estes itens sendo oferecidos a uma freqüência de três vezes por semana.

Para as coletas das formigas ( $n=43$ visitas) foram utilizadas quatro metodologias: aspirador entomológico (adaptado de um aspirador para computador); auxílio de uma seringa com água para o desalojamento da colônia e posterior captura manual com pincel; tijolos perfurados preenchidos por serrapilheira ( $\mathrm{n}=10$ tijolos) e sacos de lixo de cor preta $(\mathrm{n}=3$ sacos$)$. Nas duas últimas metodologias, estes itens foram colocados nas proximidades do ninho ou da trilha de forrageamento, e permaneceram no local por várias semanas.

Na manutenção de P. longicornis em laboratório foram avaliados: os tipos de recipientes onde as colônias permaneceriam alojadas e os itens alimentares que comporiam a dieta. Os recipientes testados foram: caixa de madeira $(10,5 \mathrm{~cm}$ de comprimento; $8,5 \mathrm{~cm}$ de largura e $1,5 \mathrm{~cm}$ de altura); placa de Petri com molde de gesso $(9,0 \mathrm{~cm}$ de diâmetro e $1,5 \mathrm{~cm}$ de altura) e tubo de ensaio, cuja extremidade fechada estava preenchida com algodão embebido em água ( $20 \mathrm{~cm}$ de comprimento e 2,2 cm de diâmetro). Para cada tipo de recipiente foram utilizadas cinco colônias, sendo que em cada colônia havia entre 50 e 150 operárias, uma rainha, além da cria. As colônias foram acompanhadas durante três meses, verificando se neste período haveria a mortalidade da colônia. Para os testes de atratividade alimentar foram utilizadas 11 espécies de insetos, 28 itens da alimentação humana e 4 dietas 
utilizadas na criação das formigas (Quadro1). Nestes testes foram utilizadas cinco colônias deP. longicornis, sendo que, em cada colônia havia, entre 300 e 600 operárias, 1 a 4 rainhas, além da cria. Os itens alimentares eram expostos individualmente durante $20 \mathrm{~min}$, sendo que ao final da exposição foi contabilizado o número de operárias sobre os itens. Por meio de observações prévias do forrageamento foi determinado um nível de atratividade, sendo que um número inferior a 5 operárias era considerado baixa atratividade, entre 5 e 15 operárias considerado média atratividade e superior a 15 operárias, alta atratividade.

\section{RESULTADOS E DISCUSSÃO}

\section{Coleta de colônias}

Nas coletas das colônias a metodologia mais adequada foi aquela em que se utilizou o aspirador entomológico. Os ninhos de P. longicornis são principalmente encontrados no peridomicílio, como por exemplo, em caixas de inspeção (esgoto, rede elétrica e gás) e paredes externas das residências. Existem dois tipos deninhos, permanentes e temporários. Os ninhos permanentes são maiores e apresentam todas as castas, enquanto que nos temporários existem apenas operárias e cria (Solis et al., 2007). Os ninhos encontrados em caixa de inspeção eram todos permanentes, sendo que o uso do aspirador entomológico possibilitou a coleta de parte do ninho (com todas as castas), e posterior continuidade deste em laboratório para as pesquisas. Assim, a utilização do aspirador foi indispensável, já que, com a abertura da caixa, as operárias fugiam rapidamente com os imaturos e as rainhas.

As armadilhas constituídas de tijolos perfurados preenchidos com serrapilheira possibilitaram apenas a coleta de ninhos temporários. Nos ninhos encontrados nas paredes das casas, não foi possível realizar a sua retirada por completo. Mesmo com a colocação de água nas frestas com o auxilio de uma seringa para o desalojamento da colônia, obteve-se apenas parte da colônia, que consistia de operárias e cria. Quando estas colônias foram transferidas para o laboratório, não houve o desenvolvimento de alados, regredindo continuamente até sua extinção. Mas, quando ovos de $P$. longicornis foram oferecidos para as colônias, em algumas, houve o surgimento de rainhas, que sobreviveram apenas algumas semanas.

Com os sacos de lixo, nada foi coletado. Ao contrário, na Colômbia, esta metodologia foi utilizada com sucesso para P. fulva, por meio da disposição de sacos plásticos pretos no campo, que constituiriam como locais preferenciais de formação de ninhos (ZENNERPolania, 1990).

\section{Tipos de recipientes}

Na manutenção das colônias de P. longicornis em laboratório, o recipiente que mostrou ser mais adequado foi o tubo de ensaio com algodão embebido em água, sendo que após três meses, todas as cinco colônias estavam ainda vivas. Nas placas de Petri com molde de gesso, três das colônias originais ainda estavam vivas, enquanto que nas caixas de madeira, apenas uma continuava viva. Mas em todas, o número de operárias se reduziu. Este teste foi anterior às infestações de ácaros, que será discutido no tópico a seguir.

A sobrevivência das colônias nos recipientes pode estar diretamente relacionada com as condições de maior umidade, proporcionadas tanto pelo algodão embebido em água como pelo gesso. Mas essa maior umidade associada à presença de uma lixeira no interior dos recipientes, característico desta espécie quando criada em laboratório, proporcionou a presença de insetos como Megaselia scalaris (Diptera: Phoridae) (Solis et al., 2005) e de ácaros.

Desta maneira, para a utilização de tubos deensaios na criação de $P$. longicornis, faz-se necessário um acompanhamento rigoroso, com a limpeza constante dos tubos, para que tais artrópodes não causem interferências nos ninhos desta formiga.

\section{Infestação por ácaros}

Ocorreram duas infestações de ácaros das famílias Acaridae, Macrochelidae (gênero Macrocheles) e Uropodidae nas colônias de P. longicornis em laboratório, provenientes da criação de insetos que serviam de alimento (A. kuehniella e T. molitor). Na primeira infestação, das 26 colônias existentes, apenas 3 sobreviveram. Na segunda infestação, das 23 colônias, apenas 12 sobreviveram.

Em laboratório, os ninhos (tubos de ensaio) de $P$. longicornis são caracterizados por serem espacialmente divididos em um local de lixeira, que se amplia com o tempo, e outro com presença de imaturos e das rainhas. Podem existir também lixeiras nas áreas externas, em várias regiões da bandeja (Solis et al., 2005). A presença da lixeira contribuiu para o estabelecimento dos ácaros nos ninhos, que se alimentam dos restos ali existentes (indivíduos mortos e restos alimentares). Além da lixeira, as condições de umidade no interior da colônia também favoreceram o desenvolvimento dos ácaros, já que nas lixeiras externas os ácaros não foram visualizados. Estes ácaros podiam atacar os imaturos, sendo observados alimentando-se de ovos e pupas. Além disso, os ácaros foram observados sobre os adultos, preferencialmente sobre as operárias, normalmente em grande quantidade, ocasionando desequilíbrio no comportamento social. 
A ocorrência dessas infestações não foi surpreendente, pois a presença desses artrópodes em ninhos de formigas é comum, sendo o grupo mais representativo dentre os mirmecófilos. Por eles serem de pequeno tamanho, não encontram dificuldade em invadir os ninhos de formigas. Os ácaros podem atuar como predadores, detritívoros, ou como ectoparasitos, vivendo sobre o corpo de adultos e larvas (HöLLDOBLER; Wilson, 1990). Relatos deácaros em ninhos deformigas foram feitos para os gêneros Aphaenogaster, Crematogaster, Eciton, Formica, Lasius, Myrmecia, Solenopsis, Tetramorium (HöLldobler; Wilson, 1990) e Atta (Della Lucia et al., 1993). Em ninhos de Atta, os ácaros de vários táxons vivem nas lixeiras, sendo que alguns podem tambématuar como predadores deovos (Della Lucia etal., 1993) e serem foréticos sobre operáriasealados, proliferando-se para outros locais (WALLER; Moser, 1990). O gênero Macrocheles é um grupo cosmopolita, cujos membros habitam uma variedade de locais, tais como: solo, serrapilheira, musgo, esterco, madeira podre, galerias de besouros xilófagos, ninhos de vertebrados (aves e mamíferos) e de insetos sociais. Estes ácaros podem realizar foresia sobre insetos das ordens Coleoptera, Diptera e Hymenoptera (CONNOR; KLimov, 2004). Por exemplo, os ácaros deste gênero foram encontrados em ninhos de Atta texana (Della Lucia et al., 1993), Eciton (Hölldobler; WiLson, 1990) e $P$. fulva (GonzAlEz et al., 2004), podendo atuar como foréticos e ectoparasitos de adultos e imaturos.

Ambas as infestações foram controladas com dificuldade, retirando-se periodicamente o lixo acumulado pelas formigas no interior das colônias e congelando $\left(-12^{\circ} \mathrm{C}\right)$ por algumas horas as larvas de T. molitor antes do oferecimento para as formigas. Mas os ácaros não devem ter sido o único fator que ocasionou a mortalidade das colônias. Comparando-se as duas infestações, a menor mortalidade da segunda infestação não deve somente ter sido influenciada pelas duas medidas citadas anteriormente, mas também, pela influência da diversificação na alimentação oferecida para as colônias, como será discutido a seguir.

\section{Alimentação}

A alimentação realizada apenas com adultos de $A$. kuehniella, larvas de T. molitor eaçúcar diluídoemágua a $25 \%$ não se mostrou satisfatória para a manutenção das colônias de $P$. longicornis, devido à elevada mortalidade. Assim, foi necessário testar outros itens alimentares para a criação desta espécie de formiga. Foram testados itens comumente encontrados em lixeiras de residências, insetos mortos e dietas específicas para a criação de formigas em laboratório (Quadro 1).

Como também observado em campo (Solis et al., 2007), em laboratório as operárias têm preferências por líquidos açucarados, provavelmente, para suprir a ausência do "honeydew" produzido pelos "homópteros", e por insetos mortos, principalmente por cupins. Em geral, itens que constituem normalmente a alimentação humana dificilmente são coletados, principalmente os sólidos. Na manutenção de colônias de formigas em laboratório para a realização de análises básicas de biologia, o uso de uma dieta equilibrada em carboidratos, proteínas, lipídeos e vitaminas é fundamental, pois as operárias têm maior necessidade por fontes de carboidratos, enquanto as larvas e rainhas por proteínas e lipídeos (Fowler et al., 1991).

Quadro 1 - Atratividade de diferentes itens alimentares pelas operárias de Paratrechina longicornis, mantidas em laboratório.

\begin{tabular}{|c|c|}
\hline Atratividade & Itens alimentares \\
\hline Alta & Ninfas de operárias de cupins (gêneros Coptotermes, Heterotermes e Cornitermes). \\
\hline Média & $\begin{array}{l}\text { Caldo de cana-de-açúcar; sangue de frango; açúcar refinado diluído em água a 25\%; arroz cozido; } \\
\text { açúcar invertido diluído em água a 70\%; adultos eninfas deBlatella germanica(Dictyoptera: Blattellidae); } \\
\text { larvas de Tenebrio molitor; adultos deAnagastakuehniella; adultos deGryllus sp. (Orthoptera: Gryllidae); } \\
\text { larvas de Zophobas sp. (Coleoptera: Tenebrionidae). }\end{array}$ \\
\hline Baixa & $\begin{array}{l}\text { Mel silvestre puro; mel silvestre diluído em água a 50\%; gema de ovo de galinha em pó; gema de ovo } \\
\text { de galinha em pó diluído em água a } 50 \% \text {; gema-de-ovo de galinha; clara-de-ovo de galinha; leite de } \\
\text { vaca puro (tipo A); óleo de amendoim; açúcar refinado puro; salsicha cozida; sardinha crua; filé } \\
\text { mignon cru; atum cru; refrigerante (tipo cola); frango (cru e cozido); adultos de Spodoptera frugiperda } \\
\text { (Lepidoptera: Noctuidae); larvas de Bombyx mori (Lepidoptera: Bombycidae) em pó; larvas de B. mori } \\
\text { em pó diluído em água a 50\%; larvas deApismellifera(Hymenoptera: Apidae); ketchup; manga; laranja; } \\
\text { melancia; bacon; iogurte; maionese; doce de leite; xarope de milho; Ovomaltine }{ }^{\circledR ;} \text { leite condensado; } \\
\text { creme de amendoim; ração de gato; Mistura 1: fígado de boi desidratado, pão de ló (sabor abacaxi), } \\
\text { mel, óleo de amendoim; Mistura2:água, mel, ovo de galinha, complexo vitamínico (com e sem agar); } \\
\text { Mistura 3: farinha, peixe e outros componentes. }\end{array}$ \\
\hline
\end{tabular}




\section{AGRADECIMENTOS}

A Dra. Márcia Cristina Mendes (Instituto Biológico de São Paulo) pela identificação dos ácaros e ao CNPq pelo apoio financeiro (Processo $n^{\circ} 130283$ / 2004-5).

\section{REFERÊNCIAS}

AGOSTI, D.; JOHNSON, N.F. Antbase. 2008. Disponível em: <http://antbase.org>. Acesso em: 10 mai. 2008.

BERNDT, K.P.; EICHLER, W. Die Pharaoameise, Monomorium pharaonis (L.) (Hym., Myrmicidae). Mitteilungen aus den Zoologischen Museum in Berlin, v.63, n.1, p.3-186, 1987.

BOLTON, B.; ALPERT, G.; WARD, P.S.; NASKRECKI, P. Bolton catalogue of ants of the world: 1758-2005. Cambrigde: Harvard University Press, 2005. 1 CDROM

CAMPOS-FARINHA, A.E.C. Urban pest ants of Brazil (Hymenoptera: Formicidae). In: INTERNATIONAL CONFERENCE ON URBAN PESTS, 5., 2005, Cingapura. Proceedings of the Fifth International Conference on Urban Pests. Cingapura: 2005. p.81-84.

CONNOR, B. O.; KLIMOV, P. Bee mites: family Macrochelidae (Acari). 2004. Disponível em: <http:// insects.Ummz.Isa.umich. edu/beemites/Species_ Accounts/Macrochelidae.htm>. Acesso em: 7 mai. 2006.

DELABIE, J.H.C.; NASCIMENTO, I.C.; PACHECO, P.; CASIMIRO, A.B. Community structure of houseinfesting ants (Hymenoptera: Formicidae) in southern Bahia, Brazil. Florida Entomologist, v.78, n.2, p.264-270, 1995.

DELLA LUCIA, T.M.C.; MOREIRA, D.D.O.; OLIVEIRA, M.A. Inimigos naturais e organismos associados aos ninhos. In: DELLA LUCIA, T.M.C. (Ed.). As formigas cortadeiras. Viçosa: Editora Folha Viçosa, 1993. p.131150.

EICHLER, W.D. Verbreitung und Ausbreitungsterndenzen der Pharaoameise in Mitteleuropa. Der Praktische Schädlingsbekämpfer, v.14, p.1-2, 1962

EICHLER, W.D. Die Verbreitung der Pharaoameise in Europa. Memorabilia Zoologica, v.29, p.31-40, 1978.

FOWLER, H.G.; FORTI, L.C.; BRANDÃO, C.R.F. DELABIE, J.C.; VASCONCELOS, H.L. Ecologia nutricional de formigas. In: PANIZZI, A.R.; PARRA, J.R.P. (Ed.). Ecologia nutricional de insetos e suas implicações no manejo de pragas. São Paulo: Manole, 1991. p.131223.
FOWLER, H.G.; BUENO, O.C.; SADATSUNE, T.; MONTELLI, A.C. Ants as potencial vectors of pathogens in hospitals in the state of Sao Paulo, Brazil. Insect Science and Its Application, v.14, n.3, p.367-370, 1993.

GONZALEZ, V.E.; GOMEZ, L.A.; MESA, N.C. Observations on the biology and behavior of the mite Macrodinychus sellnicki (Mesostigmata: Uropodidae), ectoparasite of the crazy ant Paratrechina fulva (Hymenoptera: Formicidae). Revista Colombiana de Entomologia, v.30, n.2, p.143-149, 2004.

HÖLLDOBLER, B.; WILSON, E.O. The ants. Cambrigde: Harvard University Press, 1990. 732p.

LISE, F.; GARCIA, F.R.M.; LUTINSKI, J.A. Association of ants (Hymenoptera: Formicidae) with bacteria in hospitals in the State of Santa Catarina. Revista da Sociedade Brasileira de Medicina Tropical, v.39, n.6, p.523526, 2006.

MOREIRA, D.D.O.; MORAIS, V.; VIEIRA-DA-MOTTA, O.; CAMPOS-FARINHA, A.E.C.; TONHASCA JUNIOR, A. Ants as carriers of antibiotic-resistant bacteria in hospitals. Neotropical Entomology, v.34, n.6, p.999-1006, 2005.

PASSERA, L. Characteristic of tramp species. In: WILLIAMS, D.F. (Ed.). Exotic ants: Biology, impact and control of introduced species. San Francisco: Wetsview Press, 1994. p.23-43.

ROBINSON, W.H. Urban Entomology - Insect and mite pests in the human environment. London: Chapman \& Hall, 1996. 430p.

SILVA, E.J.E.; LOECK, A.E. Ocorrência de formigas domiciliares (Hymenoptera: Formicidae) em Pelotas, RS. Revista Brasileira de Agrociência, v.5, n.3, p.220-224, 1999.

SOLIS, D.R.; REISS, I.C.; BUENO, O.C.; GOMES, L. Ocorrência de Megaselia scalaris (Loew, 1866) (Diptera, Phoridae) em ninhos de laboratório de Monomorium pharaonis (Linnaeus, 1758) e Paratrechina longicornis (Latreille, 1802) (Hymenoptera, Formicidae). Revista Brasileira de Zoociências, v.7, n.2, p.339-343, 2005.

SOLIS, D.R.; BUENO, O.C.; MORETTI, T.C.; SILVA, T.F Observações em campo sobre a biologia da formiga invasora Paratrechina longicornis (Latreille, 1802) (Hymenoptera, Formicidae). Revista Brasileira de Zoociências, Juiz de Fora, v.9, n.1, p.75-80, 2007. TRAGER, J.C. A revision of the genus Paratrechina (Hymenoptera: Formicidae) of the continental United States. Sociobiology, v.9, n.2, p.51-162, 1984.

WALLER, D.A.; MOSER, J.C. Invertebrate enemies and nest associates of the leaf-cutting ant Atta texana (Buckley) (Formicidae, Attini). In: MEER, R.K.V.; JAFFE, K.; CEDENO, A. (Ed.). Applied Myrmecology - A world perspective. San Francisco: Westview Press, 1990. p.255-273. 
ZARZUELA, M.F.M.; RIBEIRO, M.C.C.; CAMPOS-

FARINHA, A.E.C. Distribuição de formigas urbanas em um hospital da região sudeste do Brasil. Arquivos do Instituto Biológico, São Paulo, v.69, n.1, p.85-87, 2002.

ZENNER-POLANIA, I.Z. Biological aspects of the "Hormiga loca", Paratrechina (Nylanderia) fulva (Mayr), in Colombia. In: MEER, R.K.V.; JAFFE, K.; CEDENO, A. (Ed.). Applied Myrmecology - A world perspective. San Francisco: Westview Press, 1990. p.290-297.

Recebido em $1 / 2 / 07$

Aceito em 11/5/08 